\title{
Novel and Optimized Techniques for Storage and Transportation of Hydrogen: Perspectives and Challenges
}

\author{
Saadat Ullah Khan Suri ${ }^{1}$, Mohammad Siddique ${ }^{1}$ \\ Department of Chemical Engineering, Balochistan University of Information Technology, Engineering and \\ Management Sciences Quetta, Pakistan.
}

Corresponding Author: sadaat.ullah@buitms.edu.pk

\begin{abstract}
The hydrogen possesses high calorific value and it is necessary to utilize this energy due to current energy based resources depletion. It elaborates the paramount importance of hydrogen as a future renewable fuel. There are used different techniques for hydrogen storage and its transportation. In transportation techniques, there are high pressure compression and liquefaction from pipelines. On the other hand, there is developed an optimized model which fulfills the challenges by regarding hydrogen transportation with its low cost. The prominent practiced hydrogen storage techniques are; Adsorption, Casting on alloys, Absorption and Metal hydride reactor. These techniques can store hydrogen from $1.28 \mathrm{wt}$. \% to $19.6 \mathrm{wt} . \%$. Hence, the need to transport hydrogen through storage has become possible by attaining the challenges. It is an unprecedented and welcomed result declaration with highly precise evaluation
\end{abstract}

Keywords: Hydrogen Transport, Optimized model, Adsorption, Absorption and Metal Hydride reactor.

Date Received 13 May 2019

Date Accepted 11 June 2019

Date Published 5 July 2019

\section{INTRODUCTION}

Till the present time, hydrogen is used in different industrial applications by including (Thermal treatment of metals and Energy generation). It is also commercially used as energy storage. Its demand has grown up from rapid industrial developments. While hydrogen has high energy density and non-pollutants [1-3].

The hydrogen is a reliable energy carrier through its high calorific value. It is strongly interconnected with the performance of its supply chain components. In this regard, it is necessary to achieve the only reliable storage and transportation methods to enhance hydrogen market value. The usage of hydrogen as an energy carrier arises to facilitate the transition of fossil fuels to this renewable energy resource. It keeps a dominant role in engines due to its combustible nature. Henceforth, there is a growing interest for hydrogen consumption as a fuel due to its (High environmentally friendly, Sustainability nature and Abundance). Hydrogen is stored for transportation in a compressed form and there is need for development of safe and efficient storage and transportation mediums [4].

Hydrogen as a fuel cell is commercialized in light duty markets. It is also developed to use for zero emission medium in heavy duty vehicles like buses as a fuel cell. The availability of raw fuel has a role to bring hydrogen as a potential energy resource. There is need to establishing a widespread infrastructure as a new hydrogen supply system in different parts of the world. The new building transport medium seems to be very expensive and unsafe [5].

The continue dependencies on fossil fuel have adverse effect on environment. It can lead to various disasters by including (Forest fires and Hurricanes). Thus, It is crucial to develop highly efficient and environment friendly resource with sound storage and transportation techniques. The efficiency of hydrogen is $60 \%$ as compared to the other fuels by including (Gasoline and Diesel). They are energy efficient up to $22 \%$ and $45 \%$ respectively. It demonstrates that hydrogen can be used as an alternative energy resource in the upcoming time [6-7].

There are (Chemical, Physical and Electro-chemical) storage methods of hydrogen which can store it in a solid form. There are two basic types of chemical process mechanisms, which can store hydrogen on materials in a reversible manner; these are (Adsorption and Absorption). In the adsorption process, the hydrogen molecules sustain in a physical contact form with the relevant material. While in absorption, It is chemically attached to a given material. It leads to bulk storage of hydrogen in the materials by including (Metal hydrides, Lithium borohydride and Potassium alanates). There are being developed different single and multi-dimensional models to regulate the 
(Equilibrium, Transport and Reaction kinetics) conditions in storage and transportation methods. The key factor in storage method includes (Thermal management system configuration, Temperature and Reactor operating conditions). Each hydrogen storage process mechanism has its own slight limitation different to another by including (High volume of hydrogen, Weight of metal hydrides and Evaporation). Currently, there are numerous studies which describe the feasibility of hydrogen storage mechanisms. These studies are upgrading its storage yields which had practiced from researchers. This present hydrogen storage study is based on perspective and challenges on the novel hydrogen transportation and storage methods which are relevant to their (Significance, Sustainability, Kinetics investigation and Attained gaps) [8-10].

The transport sector is facing various challenges to produce a stable and environmentally friendly region. On the other side, there is increase energy requirement in the transportation sector at present. For instance, there is increase in energy demand with a comparison to its consumption in the transport sector in Germany since 25 years. Its usage value is increased from $26.1 \%$ to $29.8 \%$ between 1990 to 2015 respectively.

There is a need to build an optimum model by describing the transportation network of hydrogen with its specific demand. The Scandinavian Common Strategy (SCS) is used to investigate the potential developments in hydrogen transportation mediums. The main goal is to optimize the transportation pathways by meeting the fixed hydrogen demand and its consumption. Hence, a developed methodology is being attained which can meet the storage and transportation demand of hydrogen by having a paramount significance.

The basic mechanism for the transportation includes the various road transportation networks. The feasibility of the project includes the cost effectiveness in a particular region. The economic value of this transportation medium elaborates the requirement of hydrogen energy systems by overcoming the energy crisis significantly [11].

\section{Optimized Techniques of Hydrogen Transportation 2.1 Hydrogen Transportation:}

Wijk did the research study to describe a methodology by regarding the transportation of hydrogen in Nederland. In this postulated study, the Gansuine Transport Services have evaluated the high pressure gas infrastructure which can be used to transport hydrogen in Nederland. This is a very feasible point of view by regarding the hydrogen transportation.

The hydrogen can be transported through natural gas pipelines in northern areas from there it can be transported to the other areas. The hydrogen produced from different industrial processes in Rotterdam city can overtake the current producing 'Grey' hydrogen from Natural gas with (80-100) $\mathrm{m}^{3}$ million per annum. This raw hydrogen can also be transported through hydrogen pipelines network to Antwerp city and to France northern areas.

There are other back up techniques to generate electricity from the hydrogen at Rotterdam's Port Industrial Complex into (Ethylene and Methanol) chemicals. It can be transported through pipelines network to the Ruhr city [12].

\subsubsection{Compression:}

The main objective to transport a gas is through high pressure compression. Hydrogen can be transported through compression via (Cylinder and Pipelines). There is employed high pressure for this transportation. For instance, the $1.8 \mathrm{~kg}$ of hydrogen is transported at $40 \mathrm{MPa}$ and it takes as an expensive process demonstrated in below figure 1 .

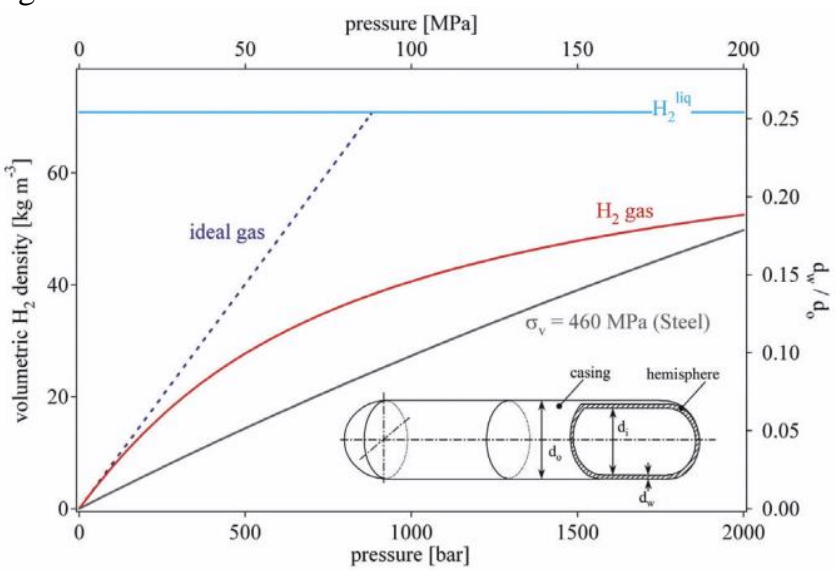

Fig. 1. Illustration on hydrogen storage from high pressure compression.

There is achieved low hydrogen volumetric density at $50 \mathrm{~kg} / \mathrm{m}^{-3}$ with compression. It is a drawback which limits its viability [13].

A large amount of energy necessary for the liquefaction and the continuous boil-off of hydrogen limit the possible use of liquid hydrogen storage systems to the applications where the cost of hydrogen is not an issue. The gas is consumed in a lower time. For example; Air and Space applications.

There is required high energy to store hydrogen from the liquefaction process which limits this process feasibility. Liquid hydrogen is transported by using special double walled insulated tanks to prevent boil off of its liquid phase. Some transport tankers also use liquid nitrogen that acts as the heat shields to cool the outer surface [14].

\subsection{Perspectives in Hydrogen Demand and Transportation:}

The annual hydrogen demand in France and Germany between 2030 and 2050 are shown in below figure 2 with maximum and minimum values. It determines the hydrogen demand in the Fuel Cell Vehicles which consume 4 to $6 \mathrm{~kg}$ of hydrogen by completing $500 \mathrm{~km}$. It is calculated from empirical correlation; $\mathrm{d}_{\mathrm{y}}(\mathrm{i})=\mathrm{P}_{\text {opy }}(\mathrm{i}) * \mathrm{D}_{\text {travel }}(\mathrm{y}) * \mathrm{~F}_{\text {range }}$ *P $\mathrm{P}_{\mathrm{FCEV}}$.

$D_{\text {travel }}$ is the average distance travelled by a person in a number of population $\mathrm{P}_{\text {opy }}(\mathrm{i})$. While, $\mathrm{D}_{\text {travel }}(\mathrm{y})$ is the total distance travelled in a year. The major objective in the population projection in Europe is that it needs hydrogen as a renewable energy resource.

The hydrogen infrastructure determines the potential resources via demand and long term energy based strategies.

\subsubsection{Transportation Methods:}




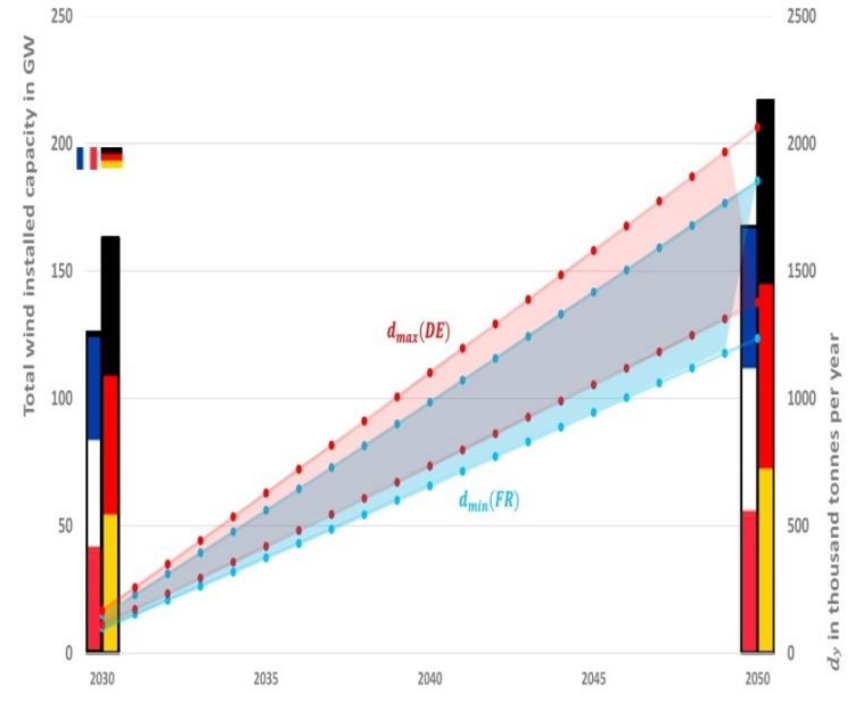

Fig. 2. Illustration on total wind capacity and hydrogen demand in Germany between 2030 and 2050.

In France and Germany, the production of hydrogen is dependent on excess electricity from wind and nuclear energy [15].

\subsubsection{The Challenges on Optimization of Hydrogen Transportation:}

Lahnaoui, Wulf, Heinrichs and Dalmazzone did the research study by developing an improved methodology for hydrogen transportation. There come optimum parameters which fulfil with low transportation cost [16].

There is used single-objective optimization to find out the lower cost of hydrogen infrastructure by regarding its transportation. The total cost consists of capital and operational cost for whole transportation process. It is interlinked with storage and compressed facilities in this mobile mode.

This study main investigation is to develop a cost effective hydrogen transportation mode. It could enable through compressed trucks and got completed till 2050 in Federal State (North Rhine-Westphalia) at Germany. This optimization is based on the hydrogen production and its consumption values. The problem focuses on the minimum cost by establishing hydrogen infrastructure under given levels of its production and consumption.

The hydrogen demand estimation is based on a European energy scenario that outlines the share of hydrogen in the mobile mode between 2035 and 2050.

A fixed level of hydrogen production is being taken from the electrolysis process mainly from the excess wind energy at Germany.

Once these parameters are fixed, the minimum cost is found to link the different production and distribution points by taking into account with (Intermediate storage and Compression) costs.

To this end, the different transportation modes have distinguished by covering two types of transport; i) a road network and b) a pipeline system. The road transportation network is the main focus of this optimization study and it is based on the existing road network. The physical state of hydrogen is determined via linear optimization presented in the model section. The costs related to the different truck components can be calculated by using the input parameters. Once these four parameters have been presented, a network is being established which is based on the transportation of hydrogen via trucks and applied to NRW [17].

\subsubsection{Sustainability in Transport Sector:}

The sustainability in the transport sector is being achieved by using hydrogen as a fuel in cars at Germany. There are various features that appeal to the volubility of the fuel by including (Refueling time and High consumption time).

The major importance of Fuel Cell Electric Vehicle (FCEV) has got raised in the present time. In general, The Battery Electric Vehicle (BEV) has some advantages for an urban area design infrastructure due to its demand.

Therefore, the potential breakthrough for (FCEV) should be taken seriously. Obviously, this has major consequences for our thinking about urban design and in particular with the level of demand for (BEV) charging points.

A research department at the Jülich Research Institute at Wilhelm-Johnen-Straße at Germany has evaluated a a survey for about 2 billion cars fleet. The hydrogen as fuel in this fleet would be least costly with whole of Germany. A total fleet of cars by providing electric charge to them is demonstrated in below figure 3 .

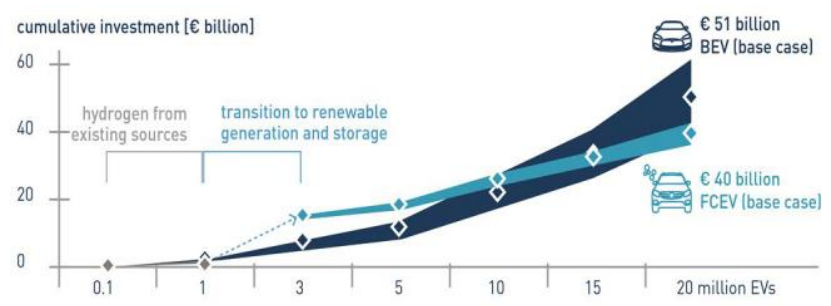

Fig. 3. Illustration on cost evaluation of hydrogen fuel in comparison to electric charging with the size of the vehicle in Germany.

The major facts demonstrated from the a survey in figure 3 states that a single hydrogen filling unit can be used as fuel in many cars with a comparison to the electric charge fillings. One important point to note here is that a one hydrogen filling point can serve many more cars per day than one electric point [18].

\subsection{Hydrogen transportation model optimization:}

Lehnaouvi, Wolf and Dalmazzone did the research study to develop a model by optimizing hydrogen transportation via truck from the forecast energy scenario. It has the focus by minimizing the (Capital, Operation and Transportation) costs.

In this model, there are used different stages by including pressure and aggregation with liquefaction process and compression. It also has a focus on primary study by optimizing pipeline as storage. It consists of four primary models which comprise of demand estimation, hydrogen production, transportation and storage [19].

The calculation is carried out from integer linear program by elaborating the objective element. To conclude, there is optimized development of road transportation which is interconnected to pipeline network with France and Germany energy results.

A fixed hydrogen demand is being obtained through energy reports in Germany and France. The excess of hydrogen will be imported. After getting fixed the input parameters, the minimum cost can be found from intermediate storage 
and transportation costs through hydrogen production and its distribution point.

The hydrogen transportation by using truck transport network depends on road networks. In below figure 4 , the road network is a part of graph $\mathrm{G}(\mathrm{N}, \mathrm{V})$. There are $\mathrm{N}$ nodes and $\mathrm{V}$ vectors that interconnect these nodes. These nodes consist of production nodes $\mathrm{P}$. It determines the location and production flow of hydrogen $\mathrm{P}_{\mathrm{i}}$. The hydrogen at initial state is denoted by $\left(\mathrm{S}_{\mathrm{o}}\right)$. A set of distribution with nodes $\mathrm{D}$ determines the location and flow demand $\left(\mathrm{d}_{\mathrm{i}} \mathrm{f}\right)$ hydrogen. The charging cost of hydrogen from $\mathrm{S}$ to $\mathrm{S}^{\prime}$ states are determined from $\left(\mathrm{C}_{\mathrm{i}}^{\mathrm{ss}} * \mathrm{~S}_{\mathrm{t}}^{\mathrm{i}}\right)$. The total cost is calculated from $\mathrm{C}_{\mathrm{i}}^{\mathrm{SS}}$ ' shown in below figure 4 . The transportation cost of hydrogen $\mathrm{Q}_{\mathrm{ij}}^{\mathrm{s}}$ is calculated from node $\mathrm{i}$ to $\mathrm{j}$ at road transportation on the present physical state. The physical state $\left(\mathrm{S}=\mathrm{C}_{\mathrm{ij}} \mathrm{S}^{\mathrm{S}} * \mathrm{Q}_{\mathrm{ij}} \mathrm{S}^{\mathrm{S}}\right)$ can be defined as a cost function of hydrogen transportation.

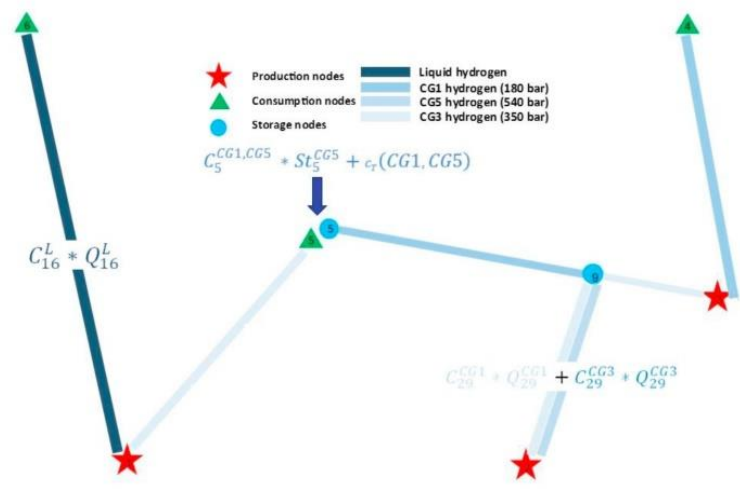

Fig. 4. Illustration on derived models for transportation of hydrogen.

\section{Challenges Met at Hydrogen Storage Studies with Process Selectivity: \\ 3.1 Materials:}

At present time, there is a challenge to store hydrogen. There are six storage methods by including (High pressure gas cylinder, Liquification, Adsorption, De-sorption and Metal hydrides) which are under investigation to improve process selectivity from scientists. The main objective is to store it in packed form as close as possible to get high volumetric density. It implies towards the volume of hydrogen gas. Thus, to increase its density; additional work has to be employed to compress the gas. The most conventional storage methods are compression and liquefaction. The absorption method includes the absorption of hydrogen on a material surface and adsorption corresponds to absorption on solid metal hydrides. These methods are reviewed extensively and valuable.

The hydrogen storage on inert substance has a feature by regarding the hydrogen can only be released if this substance is heated at $800^{\circ} \mathrm{C}$ due to covalent hydrogencarbon bonding [20].

\subsection{Hydrogen Storage Methods: \\ 3.1.1 Hydrogen Adsorption:}

Van der walls forces serve as an origin for adsorption of hydrogen gas molecules on the solid surface. The gas molecules interact with solid surface and this interaction consists of attraction and repulsion, which result by minimizing the gas molecules distance between surfaces to the power (-12) simultaneously. After the formation of monolayer of gas molecules, molecules react with solid adsorbate. For example, it is suitable to adsorbed gas components on high surface area of solid like activated carbon or Carbon Nano-tubes (CNT's). The hydrogen adsorption on CNT's can be calculated through Feynman adsorption potential and Grand Canonical Monte Carlo simulation. There is achieved $2 \%$ by mass hydrogen adsorbed capacity in CNT's. While the $0.08 \%$ of hydrogen released through desorption [20].

\subsubsection{Hydrogen storage from Adsorption:}

Carraro and Sapag [21] research study is able to store hydrogen from adsorption upto $1.23 \mathrm{wt} \%$. This study is able to elaborate the mesoporous material MSM-41 metal behavior by doping with Ni maximum with the comparison with $\mathrm{Fe}, \mathrm{Ti}, \mathrm{Mg}$ and $\mathrm{Ni}$ at $77 \mathrm{~K}$ respectively. They used UV-Vis DR spectroscopy method to understand the coordination. Hydrogen adsorption measurements at $77 \mathrm{~K}$ and pressures up to 10 bar were performed in a static volumetric system (Micromeritics Instrument Corporation), USA.

The structural characterization of the samples was performed by using X-ray diffraction in Pan Analytical Empyrean diffractometer.

\subsubsection{Hydrogen storage from Ionic liquid absorption:}

Lombarso. Hang and Zuttel [22] work is based on Borohydride and Ionic liquid (1-butyl-3methylimidazolium borohydride $\left([\mathrm{bmim}]\left[\mathrm{BH}_{4}\right]\right)$ as the combined $\mathrm{H}_{2}$ storage medium. After dehydrogenation of this compound, the desorbed $\mathrm{H}_{2}$ was found to be 2.9 wt. \% at $100^{\circ} \mathrm{C}$ demonstrated in figure 5. The $\mathrm{H}_{2}$ content of samples was identified by using PCT mass flow which was manufactured at (GRZ technologies, Switzerland).
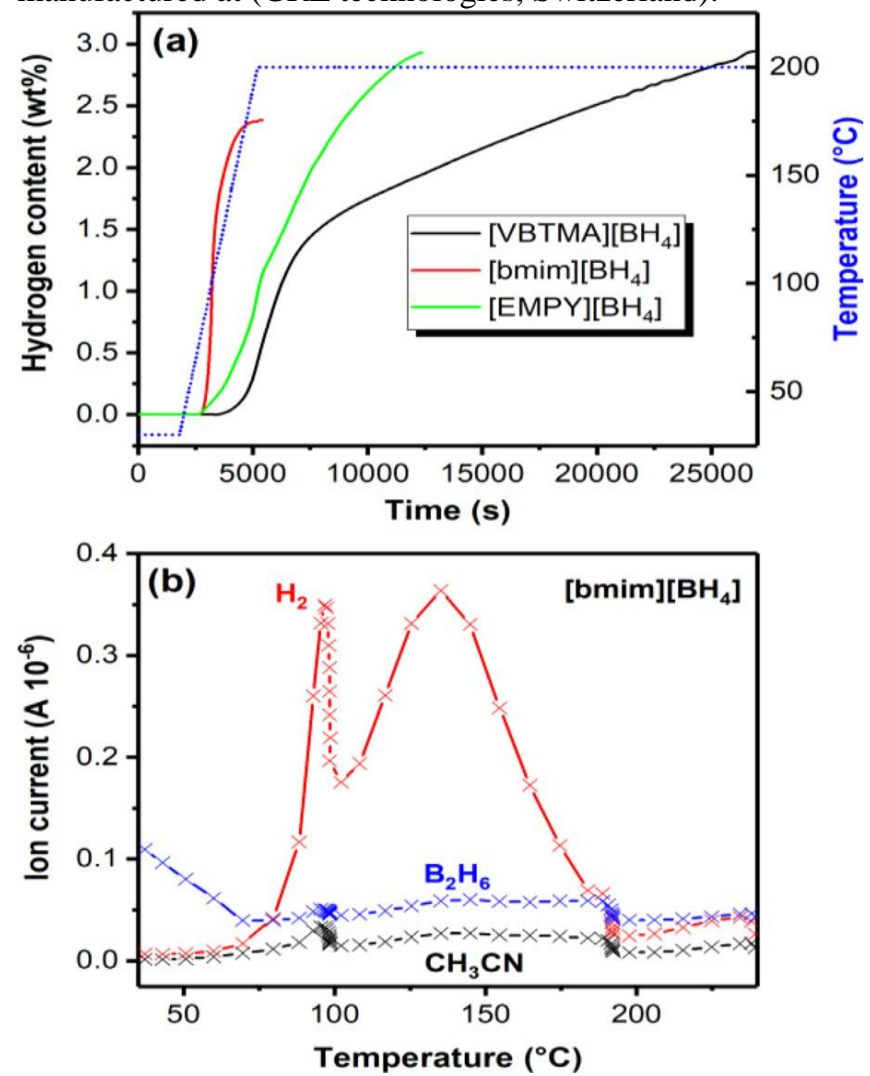

Fig. 5. (a) Illustration on hydrogen concentration analysis PCT curves as a function of time on variable 
$[\mathrm{IL}]\left[\mathrm{BH}_{4}\right]$ concentrations and (b) Hydrogen Ion analysis of ([bmim] $\left.\left[\mathrm{BH}_{4}\right]\right)$.

\subsubsection{Hydrogen storage on alloys:}

$\mathrm{Li}$ and $\mathrm{Hu}$ [23] did the research work on MgTiNi alloys to store $\mathrm{H}_{2}$. Their finding is based on MgTiNi alloys as they were capable to store $5.3 \mathrm{wt} \%$ of $\mathrm{H}_{2 . .}$ The samples of MgTiNi were produced from "Vacum" induction levitation. After it, the powder MgTiNi was subjected to hydrogenation and their dehydring behaviour was being studied from Sievert's type apparatus (PCTPro, Setaram). The hydrogen adsorption kinetics were studied at the temperature range between $250^{\circ} \mathrm{C}$ and $380^{\circ} \mathrm{C}$ by varying the time. While, $\mathrm{H}_{2}$ desorption is measured by using differential scanning (Netzsch STA449F3).

\subsubsection{Hydrogen storage from hydro-desulfurization:}

Han [24] did the research work on hydrogen storage through $\mathrm{MgH}_{2}$ supported $\mathrm{MOS}_{2}$ through hydrodesulfurization. In this work, from de-hydrogenation; the $\mathrm{H}_{2}$ storage reaches upto $10 \%$ by wt $\%$ at peak temperature of $402{ }^{\circ} \mathrm{C}$. The hydrogen is released from $\mathrm{MgH}_{2}$ reaction with Thiophene temperature range $325-400^{\circ} \mathrm{C}$. There is coupling between $\mathrm{MgH}_{2}$ decomposition and thiopenen dehydrogenation. Henceforth, this study shows the feasibility of hydrogen storage in Thiophene desulfurization of solid state.

\subsubsection{Hydrogen strage from Ammonia Borane:}

Akbayrak and Ozkar [25] did the research work to develop a material for hydrogen storage. In their research work, they find Ammonia Borane $\left(\mathrm{BNH}_{6}\right)$ as a solid material to store $\mathrm{H}_{2}$ upto 19.6 wt. \% demonstrated in below figure 6. It has high stability and non toxicity. The hydrolysis process represents the Ammonia as a suitable gas to release $\mathrm{H}_{2}$. The metallic nanoparticles catalytic action causes $\mathrm{H}_{2}$ generation from $\mathrm{BNH}_{6}$. This catalytic action provides a turnover frequency up to $2010 \mathrm{~min}^{-1}$.

There are observed different volume of released $\mathrm{H}_{2}$ from $\mathrm{BNH}_{6}$ in specific time by using Rhodium as a catalyst. It has average particles size of about 5.2 to $2.7 \mathrm{~nm}$. There is a turnover frequency of $200 \mathrm{~min}^{-1}$ at $25^{\circ} \mathrm{C}$.
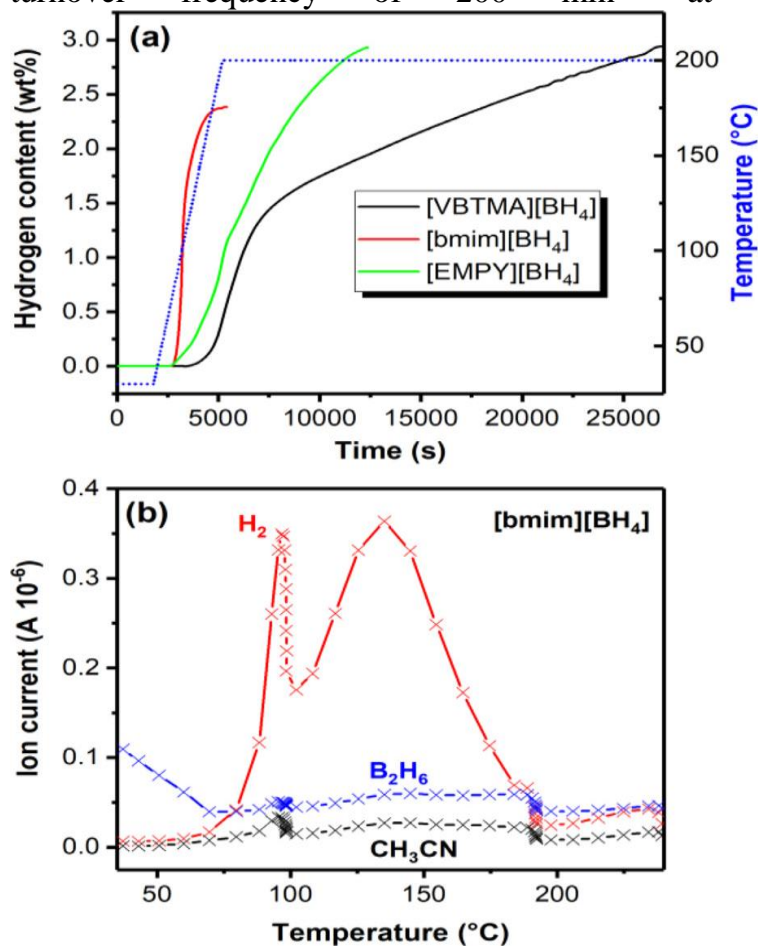

Fig. 6. Demonstration on volume of $\mathrm{H}_{2}$ stored by varying time and temperature.

The hydrolytic hydrogenation of Ammonia Borane is not a cost effective. Therefore, there are tested materials by including non- noble metal nano particles for the generation of $\mathrm{H}_{2}$ gas. The stabilization is carried out by using nonnoble metal Cobalt in the presence of Poly (N-vinyl-2pyrrolidone) (PVP) stabilizer in methanol solution. There is observed released of hydrogen from hydrolytic hydrogenation at different temperature from $25^{\circ} \mathrm{C}$ to $45^{\circ} \mathrm{C}$ in figure 7.

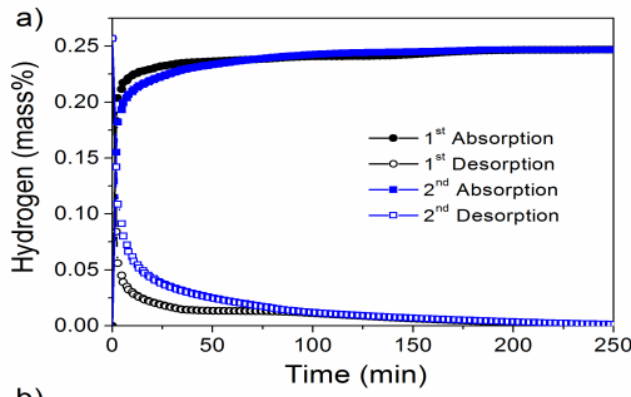

b)

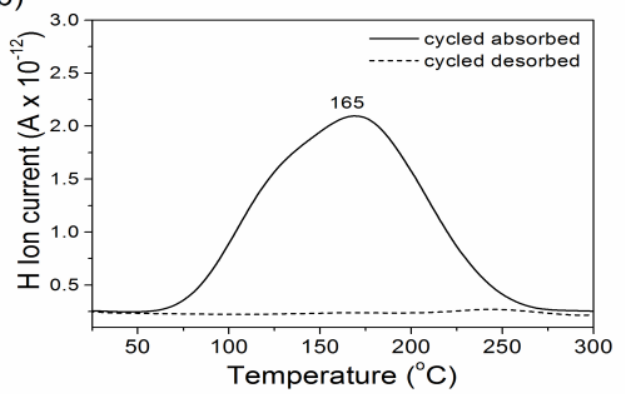

Fig. 7. Selectivity of hydrogenation process representation of with

the hydrogen from the Ammonia Borane process

time variation.

\subsubsection{Storage of hydrogen on metal:}

Lupu, Coldea, Misan, Lazar and Blantia [26] did the research work on the $\mathrm{H}_{2}$ adsorption isotherms with MIL101 metal on different pressure and temperature ranges. They concluded that MIL-101 as adsorbent optimized the $\mathrm{H}_{2}$ storages at $200 \mathrm{~K}$ and $70 \mathrm{MPa}$ for both storage and mobile applications.

Long and Xiafei [27] did the research work on Li supported $\mathrm{Be}_{3} \mathrm{C}_{2}$ as a material for hydrogen storage. In this study, the investigation on Li performance was carried out with $\mathrm{Be}_{3} \mathrm{C}_{2}$ for hydrogen storage. There is an observation that $\mathrm{Li}$ atoms are capable of strong bonding on $\mathrm{Be}_{3} \mathrm{C}_{2}$ as energetically clusters. There is attained $10.79 \mathrm{wt} \%$ of stored hydrogen density. The paramount role of strong $\mathrm{H}_{2}$ bonding is displayed from polarization and electronic hybridization. The process shows the $\mathrm{H}_{2}$ adsorption and storage capacities with Lithium supported $\mathrm{Be}_{3} \mathrm{C}_{2}$.

3.1.8 Hydrogen storage in Aluminium Hydride reactor:

Wang [28] did the research work on hydrogen storage from Aluminium Hydride $\left(\mathrm{AlH}_{3}\right)$ reactor. $\mathrm{AlH}_{3}$ reactor can store $\mathrm{H}_{2}$ due to its moderate decomposition temperature. In contrast, there is reversibility in $\mathrm{H}_{2}$ storage. It can be overcome by using nano-confinement. After this, it can be stored in nano-sized Aluminium (Al). The $\mathrm{Al}$ has mesopores of width greater contact area than graphite. The decomposition temperature of nano-confined $\mathrm{AlH}_{3}$ reactor 
is $50^{\circ} \mathrm{C}$ which is lower than its bulk. The $\mathrm{H}_{2}$ evolution is being investigated from Thermo Gravimetric Analysis (TGA). The $\mathrm{AlH}_{3}$ reactor decomposes at $170{ }^{\circ} \mathrm{C}$. The $\mathrm{H}_{2}$ desorption gets complete at $225{ }^{\circ} \mathrm{C}$. There is uniform particle distribution of nano-cofined and $\mathrm{AlH}_{3}$ materials. There is $10.1 \%$ by mass of $\mathrm{H}_{2}$ is released. It is demonstrated in below figure 8(a). There is $1.7 \$$ by mass $\mathrm{H}_{2}$ is lost due to close space between nano-confined and $\mathrm{AlH}_{3}$ materials. The total hydrogen released from material is demonstrated in figure. 8 .

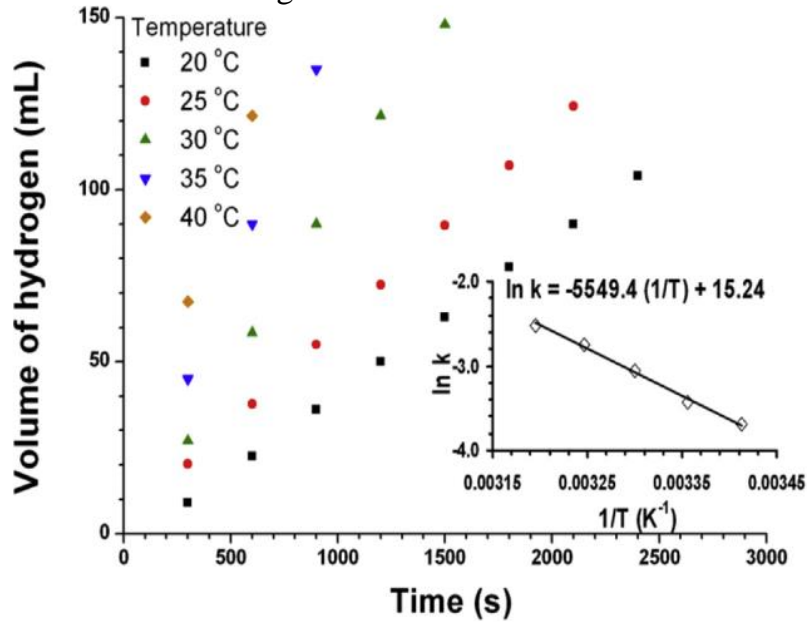

Fig. 8. Illustration on volume of hydrogen with respect to different time and temperature.

There is $0.25 \%$ of reversible $\mathrm{H}_{2}$ capacity from nanoconfined material shown in below figure 9. It shows that $15 \%$ of $\mathrm{Al}$ reabsorbed hydrogen. The $\mathrm{H}_{2}$ recycling reaction is fast as there consume 10 minutes to get $90 \%$ of the absorption. The further analysis with MS demonstrates that $\mathrm{H}_{2}$ is released at $60^{\circ} \mathrm{C}$ with highest value at $165^{\circ} \mathrm{C}$. It is being evaluated that the reversibility arises from $\mathrm{LiAlH}_{4}$ traces not $\mathrm{AlH}_{3}$. While, there is observed no reversibility at $300^{\circ} \mathrm{C}$. The nano-sizing causes destabilization of uncatalysed $\mathrm{AlH}_{3}$ with its carbon interface. Henceforth, It upgrades the storage property significantly. This study confirms that $\mathrm{H}_{2}$ releases at $60^{\circ} \mathrm{C}$ by confirming the nanoparticle effects from destabilization process effectively.
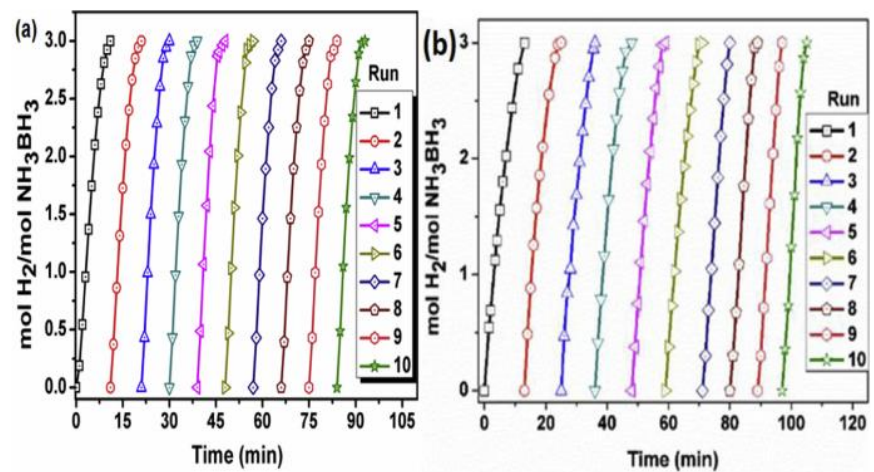

Fig. 9. Illustration on hydrogen concentration by varying time and temperature.

\subsubsection{Hydrogen storage in Metal Hydride reactor by using improved parameters:}

Bhouri, Linder and Burger [29] did the research work on Metal hydride $(\mathrm{MeH})$ reactor for $\mathrm{H}_{2}$ storage and cold production. This $\mathrm{MeH}$ system is capable to store $\mathrm{H}_{2}$ in a gaseous form. There is achieved improved cooling and heating effects. The $\mathrm{MeH}$ reactor is used to evaluate the efficiency of $\mathrm{H}_{2}$ storage at a lower temperature. There is used hydro-alloy graphite-C5 material in reactor as a reference material which is shown in figure 10 . While, there are three regions in $\mathrm{MeH}$ reactor which demonstrate the (Storage, Coupling and Cold production) of $\mathrm{H}_{2}$ simultaneously.

It is proved from the research work that there is high utilization of $\mathrm{H}_{2}$ in regime I and III. There can also produce the cooling effect in the second regime (Dual usage) on different temperature ranges.

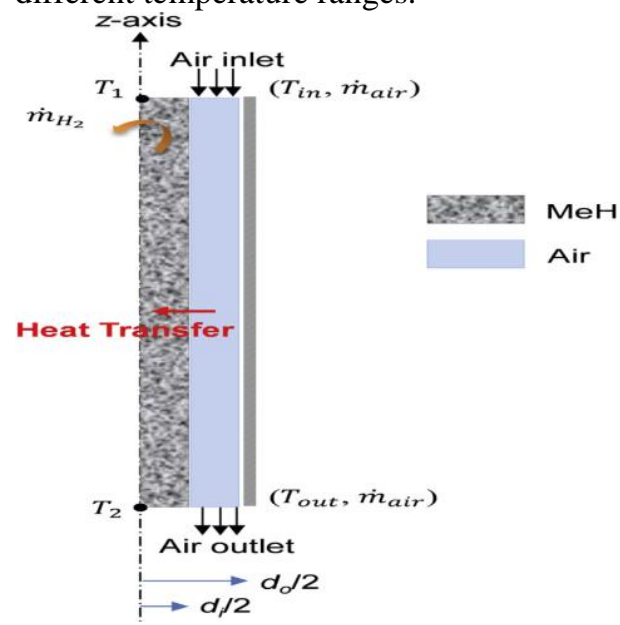

Fig. 10. 2D- Simulated geometry of a single $\mathrm{MeH}_{3}$ reactor. A simulation configuration of $\mathrm{MeH}$ reactor is shown for the hydrogen storage. This novel design offers free space in reactor for the heat distribution. There is fixed $\mathrm{MeH}$ bed by having diameter (di). The air flows though it. The outer wall is insulated there.

There is distribution of temperature on $\mathrm{MeH}$ tube along the center of the hydride bed. The temperature on the bed $\left(\mathrm{DT}_{\text {bed }}\right)$ depends on heat generated from the reaction and heat supplied to the bed in regime I and II simultaneously. There is small amount of hydrogen is transferred with comparison to stored hydrogen. The temperature gradient on the bed is described as $\left(\mathrm{DT}_{\text {bed }^{1} / 4}\right)$. It is due to the mass transfer of hydrogen. It is demonstrated from the above figure 11 that temperature gradient is uniform along the $\mathrm{z}$ axis in region I and II. The absolute temperature values are $\mathrm{T}_{\text {air;in }}$ and $\mathrm{T}_{\text {air;out }}$ it can change. The figure 11 shows the temperature with its specified location in reactor. It is necessary to get these values to have an understanding of analytical methods. There is extra heat transfer from reactor tube wall and the fluid is neglected in this analytical study. (a) Regime I

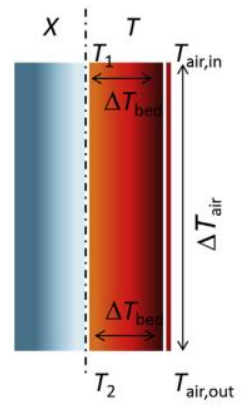

$\Delta T_{\text {air }}<1 \mathrm{~K}$

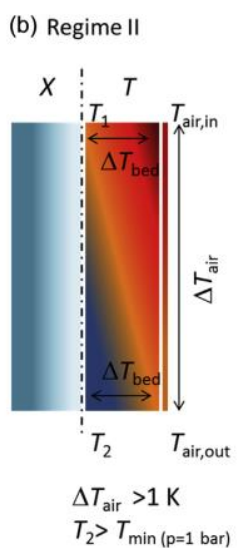

(c) Regime III

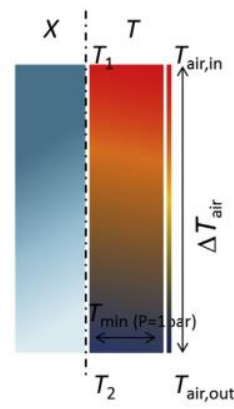

$T_{2}=T_{\min (\mathrm{p}=1 \text { bar })}<T_{1}$
Fig. 11. Schematic diagram of temperature variation and $\mathrm{H}_{2}$ conversion at three reactor regions. 
The cold production of hydrogen is observed at the lower temperature and inlet air velocity of $10 \mathrm{~m} / \mathrm{s}$. The temperature change of reactor bed is shown in below figure 12. There is observed large constant temperature difference in figure 12(b). As there is released hydrogen get increased at the temperature $\mathrm{T}_{1}$ and $\mathrm{T}_{2}$; the temperature difference gets $5^{\circ} \mathrm{C}$. The reactor system comes on steady state when the temperature difference reaches at zero.

There is observed different values of released hydrogen from $\mathrm{MeH}$ bed; it is due to lower temperature difference in regime I and II. A reaction is developed in radial direction in below figure 12(b). The temperature difference gets constant during the hydrogen released in regimes I and II. When the desorption gets completed, the temperature raises.

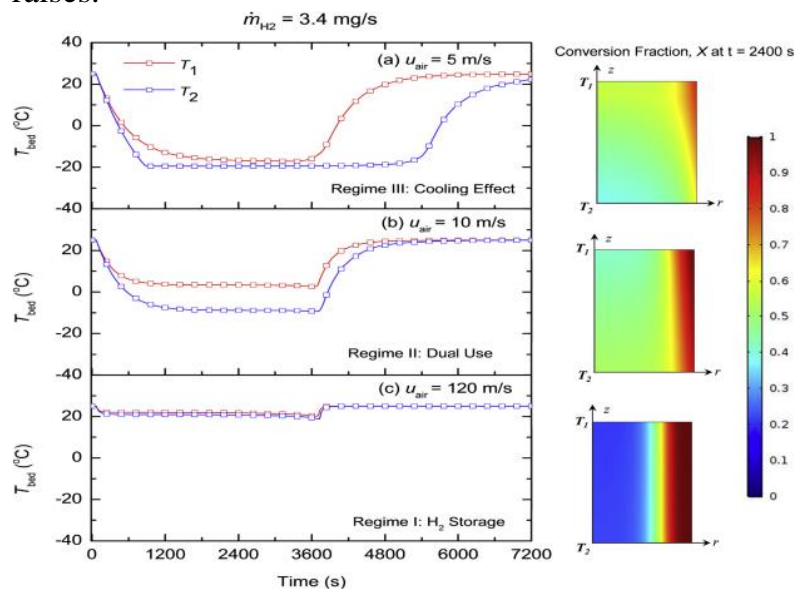

Fig. 12. Temperature effect of bed temperature at three regions with conversions of $\mathrm{H}_{2}$ at different air velocity.

There is temporary rise of temperature between $T_{1}$ and $T_{2}$ when the reactor functions as a cooling device. While, the temperature gets lower at regimes I and II with equilibrium temperature and pressure of 1 bar. The temperature $T_{1}$ is plotted on the top of this reactor is greater than equilibrium temperature. There is required one hour operation at the the fuel cell by investigating the temperature $T_{1}$ rise towards the steady state value of $25^{\circ} \mathrm{C}$. At this value, the reactor is fully discharged. The temperature $\mathrm{T}_{2}$ shows the same phenomena after 30 minutes. It demonstrates that cold production region controls the discharged $\mathrm{H}_{2}$ amount. It is anticipated that amount of desorbed $\mathrm{H}_{2}$ is plotted in $\mathrm{x}$ direction of figure 12 (a).

The each $\mathrm{MeH}$ reactor tube absorbs $\mathrm{H}_{2}$ in one hour of operation. In the same time duration, the air exits from $\mathrm{MeH}$ reactor at a temperature of about $18.5^{\circ} \mathrm{C}$. It shows the minimum temperature value under this operating condition. The total $\mathrm{H}_{2}$ mass of $34 \mathrm{mg} / \mathrm{s}$ is given to the fuel cell. There is released $122.4 \mathrm{~g}$ of hydrogen. As, the discharge rate of $\mathrm{H}_{2}$ reaches $6.8 \mathrm{mg} / \mathrm{s}$ for $2 \mathrm{KW}$ fuel cell at, there is required 5 $\mathrm{MeH}$ reactor tubes for the operation. It is necessary to maintain a constant $\mathrm{H}_{2}$ discharging rate at $6.8 \mathrm{mg} / \mathrm{s}$ with a constant outlet wall temperature of $12^{\circ} \mathrm{C}$ demonstrated in figure 13. Hence, complete discharge of $\mathrm{H}_{2}$ is attained with two sets of five MeH-air tube reactors. There is observed temperature plateau at $3300 \mathrm{~s}$ and air velocity of $5 \mathrm{~m} / \mathrm{s}$. At these intervals, there is constant release of $\mathrm{H}_{2}$. There is lowest outlet air temperature is ${ }^{\circ} \mathrm{C}$. It is due to the reactor operation in cold production region.
Henceforth, these pressure controlled tests give the valuable analysis on the maximum $\mathrm{H}_{2}$ discharged rate from the $\mathrm{MeH}$ reactor tubes. It also elaborates the paramount feature of the novel $\mathrm{MeH}$ reactor that is technically sound by keeping $\mathrm{H}_{2}$ storage and its release.

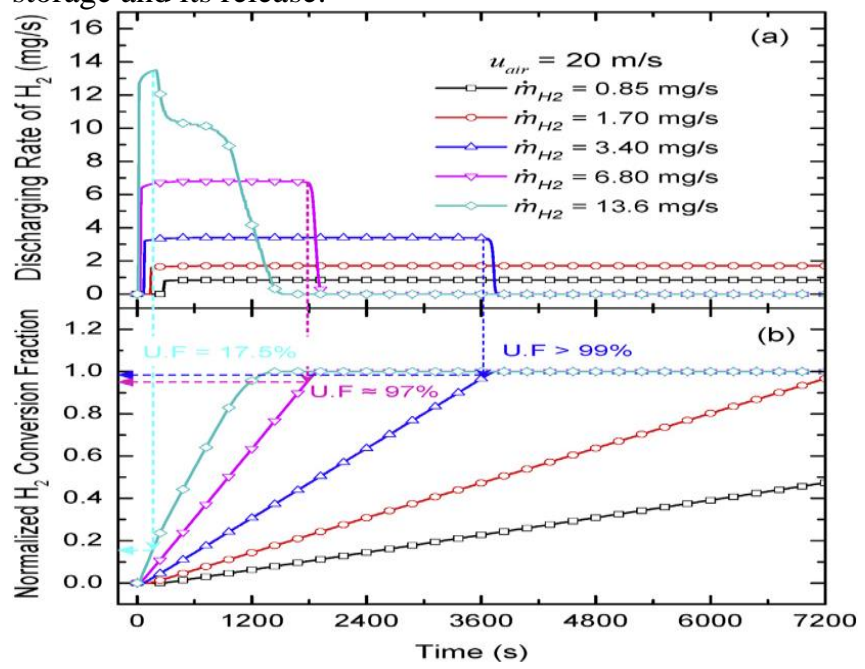

Fig. 13 Illustration on $\mathrm{H}_{2}$ discharging rate and its conversion with mass flow rate.

\section{Summary}

There has been evolved the emerging market value of hydrogen as a renewable fuel. It arises due to low content of pollutants. Thus, hydrogen fuel cell can be taken as an energy resource. The economic and refuelling design parameters are able to enhance its usage. The optimized transportation model also validates the process feasibility. The scientific studies are able to demonstrate the high storage content of hydrogen upto $19.6 \mathrm{wt}$. \%. This highest storage is achieved by using Ammonia borane as adsorbent or storage material. Henceforth, It facilitates the hydrogen storage. The Metal hydride reactor performance is transitory by releasing $97.920 \mathrm{~g}$ of hydrogen in 3 hours of operation time.

\section{Acknowledgment}

The authors are grateful to staff in department of Chemical Engineering at Buitems for their continuous support during research.

\section{REFERENCES}

[1] M. Bai , K. Song, Y. Sun, M. He, Y. Li and J. Sun, “An overview of hydrogen underground storage technology and prospects in China," Journal of Petroleum Science and Engineering, vol. 124, pp. 6-132, 2014.

[2] C. Yang and J.M. Ogden, "Renewable and low carbon hydrogen for California - Modeling the long term evolution offuel infrastructure using a quasi-spatial TIMES model," International Journal of Hydrogen Energy, vol. 38, pp. 42-50, 2013.

[3] S. Hanley, J. Deane and B.O. Gallachoir, "The role of hydrogen in low carbon energy futures e a review of existing perspectives," Renewable and Sustainable Energy Reviews, vol. 82, pp. 3027-3045, 2018.

[4] A. Almansoori and N. Shah, "Design and operation of a future hydrogen supply chain: multi-period model," International journal of hydrogen energy, vol. 34, pp. 7883-7897, 2009. 
[5] S. D. Almaraz, C. Azzaro-Pantel, L. Montastruc and S. Domenech,"Spatial-based approach of the hydrogen supply chain in the Midi-Pyrénées region, France" presented at 24th European Symposiumon Computer Aided Process Engineering, 2014.

[6] V.P. Ting, A.J.R Cuesta, N. Bimbo, E. Sharpe, N. Diaz and V. Presser, "Direct evidence for solid-like hydrogen in a nanoporous carbon hydrogen storage material at supercritical temperatures," American Chemical Society Nano, vol. 9, pp. 8249-8254, 2015.

[7] Y. Pan, S. Wang, L. Jia and X. Zhang, "First-principles study of a new structure and oxidation mechanism of Pt3Zr," Royal Society of Chemistry Advances, vol. 7, pp. 54772-74778, 2017.

[8] N.M. Konda, N. Shah, N.P. Brandon, "Optimal transition towards a large-scale hydrogen infrastructure for the transport sector: the case for the Netherlands," International Journal of Hydrogen Energy, vol. 36, pp. 4619-4635, 2011.

[9] U. Eberle, M. Felderhoff, F. Schuth, "Chemical and physical solutions for hydrogen storage," Angewandete Cheme, vol. 48, pp. 6608-6630, 2009.

[10] S. Baufumé, F. Grüger, T. Grube, D. Krieg, J. Linssen and M. Weber, "GIS-based scenario calculations for anationwide German hydrogen pipeline infrastructure," International Journal of Hydrogen Energy, vol. 38, pp. 3813-3829, 2013.

[11] E.C. Marcoulaki, I.A. Papazoglou and N. Pixopoulou, "Integrated framework for the design of pipeline systems using stochastic optimisation and GIS tools," Chemical Engineering Research and Design, vol. 90, pp. 2209-2222, 2012.

[12] V.W. Ad, "Hydrogen - the key to the energy transition," Circulariteit - Neemt dat al een vlucht, vol 1, pp. 1-5, 2018.

[13] Z. Andreas, "Materials for hydroge storage," Materials Today, vol.1 pp. 1-7, 2003

[14] The wind power. Total installed capacity. In: The wind power. 2016.

[15] Fraunhofer. Monthly electricity generation, Germany, 2016.

[16] L. Amin, W. Chiristina and D. Didier, "Building an optimal hydrogen transportation system for mobility, focus on minimizing the cost of transportation via truck," Energy Procedia, vol. 142, pp. 2072-2079, 2017.

[17] E.C. Marcoulaki, I.A. Papazoglou, N. Pixopoulou, "Integrated framework for the design of pipeline systems using stochastic optimisation and GIS tools," Chemical Engineering Research and Design, vol. 90, pp. 2209-2222, 2012.

[18] A. Almansoori and N. Shah N, "Design and operation of a future hydrogen supply chain: multi-period model," International journal of hydrogen energy, vol. 34, pp. 78837897, 2009.

[19] N.M. Konda, N. Shah and N.P. Brandon, "Optimal transition towards a large-scale hydrogen infrastructure for the transport sector: the case for the Netherlands," International Journal of Hydrogen Energy, vol. 36, pp. 4619-4635, 2011.

[20] H. Barthelem, M.Weber and F. Barbier, "Hydrogen storage: Recent improvements and industrial perspectives," International Journal of Hydroegen Energy, vol. 41, pp.1-9, 2016.

[21] P. Carraro, V. Elıas, A.A.G. Blanco, K. Sapag, G. Eimer and M. Oliva, "Study of hydrogen adsorption properties on MCM41 mesoporous materials modified with nickel," International Journal of Hydrogen Energy, vol. 39, pp. 8749-53, 2014.

[22] L. Loris, Y. Heena and Z. Andreas, "Study of borohydride ionic liquids as hydrogen storage materials," Journal of Energy
Chemistry, vol. 33, pp. 17-21, 2019.

[23] L. Yongzhi, H. Feng, L. Long, X. Jianyi, Zengwu, Zhao, Z Yanghuan and Z. Dongliang, "Hydrogen storage of casting MgTiNi alloys," Catalysis Today, vol. 318, pp. 103-106, 2017.

[24] H. Zongying, C. Heipeng, L. Xinyuan, J. Ruiqian and Z. Shixue, "Novel application of $\mathrm{MgH} 2 / \mathrm{MoS} 2$ hydrogen storage materials to thiophene hydrodesulfurization: A combined experimental and theoretical case study," Materials \& Design, vol. 158, pp. 213-223, 2018.

[25] A. Serdar, O. Saim, "Ammonia borane as hydrogen storage materials," International Journal of hydrogen energy, vol. 43, pp. $18592-18606,2018$.

[26] D. Lupu, I. Coldea, M. Misan and G. Lazar, "Blanita Hydrogen storage potential in MIL-101 at $200 \mathrm{~K}$," International Journal of Hydrogen Energy, vol. 43, pp. 1 -1 5, 2018.

C. Long, C. Xianfei, L. Jia, X. Pan, Z. Fuyu and X. Beibei, "Li decorated $\mathrm{Be} 3 \mathrm{C} 2$ as light-weight host material for reversible hydrogen storage," Applied Surface Science, vol. 459, pp. $217-$ 223, 2018.

[28] W. Lei, R. Aditya, F. Kondo and Z. Aguey, "Hydrogen storage properties of nanoconfined aluminium hydride (AlH3)," Chemical Engineering Science, vol. 194, pp. 64-70, 2019.

[29] M. Bhouri, M. Linder, and I. Burger, "Metal hydride reactor for dual use: Hydrogen storage and cold production," International Journal of Hydrogen Energy, vol. 43, pp. 23357-23371, 2018. 